\title{
Spatial Scale Transformation-based Estimation Model for Fresh Grass Yield: A Case Study of the Xilingol Grassland, Inner Mongolia, China
}

Haixin Liu ( $\sim$ gislhx@hebeu.edu.cn )

Hebei University of Engineering https://orcid.org/0000-0001-5117-3241

Anbing Zhang ( $\nabla$ zhanganbing@hebeu.edu.cn )

Hebei University of Engineering

Yuling Zhao

Hebei University of Engineering

Anzhou Zhao

Hebei University of Engineering

Dongli Wang

Hebei University of Engineering

\section{Research Article}

Keywords: Remote sensing, MODIS, Vegetation coverage, spatial scale transformation (SST), fresh grass yield (FGY)

Posted Date: March 9th, 2021

DOI: https://doi.org/10.21203/rs.3.rs-182923/v1

License: (9) (1) This work is licensed under a Creative Commons Attribution 4.0 International License.

Read Full License 


\section{Spatial Scale Transformation-based Estimation Model for Fresh}

$5{ }^{1}$ College of Mining and Geomatics, Hebei University of Engineering, Handan 056038, China;

$6{ }^{2}$ Heibei Collaborative Innovation Center of the Comprehensive Development and Utilization of Coal Resource,

7 Hebei University of Engineering, Handan 056038, Hebei, China

8 Corresponding author:

9 Haixin Liu

10 Email: gislhx@hebeu.edu.cn

11 Tel: +860310 3967616

12 Fax: +8603103968766

13 Anbing Zhang

14 Email: zhanganbing@hebeu.edu.cn

15 Tel: +8603103969519

16 Fax: +8603103969519 
19 Abstract: Estimating the grass yield of a grassland is of vital theoretical and practical significance for reasonably

20 determining its grazing capacity and maintaining its ecological balance. On that account, this paper first compares

21 model precision by adopting normalized differential vegetation index (NDVI) and net primary productivity (NPP)

22 as grass yield estimation factors, and then proposes a spatial scale transformation (SST)-based estimation model

23 for fresh grass yield (FGY) adopting NPP as its estimation factor. Next, it takes the grassland in Xilingol League,

24 Inner Mongolia as the study area for precision verification and grass yield estimation. Results indicated that: (1)

25 The precision of the model adopting NPP as the estimation factor was clearly higher than that of the model

26 adopting NDVI. (2) Through modifying NPP, the SST-based FGY estimation model could greatly improve

27 estimation precision. The relative precisions of the estimation models constructed using linear and power functions

28 were $18.16 \%$ and $18.35 \%$, respectively. (3) The estimation models constructed using linear and power functions

29 were employed to estimate the grass yield of the grassland in Xilingol League, and the total FGYs estimated by

30 them were $8.777 \times 10^{10} \mathrm{~kg}$ and $8.583 \times 10^{10} \mathrm{~kg}$, respectively. The two models obtained roughly the same estimates,

31 but there were significant differences between them in the spatial distributions of FGY per unit.

32 Keywords: Remote sensing; MODIS; Vegetation coverage; spatial scale transformation (SST); fresh grass yield 33 (FGY) 


\section{1. Introduction}

The grassland ecosystem is one of the most widely distributed ecosystems around the world, covering about $40 \%$ of land surface (Suttie et al., 2005). So far, there are approximately 400 million hectares of natural grasslands in China. Mainly distributed in the Inner Mongolia Autonomous Region (Inner Mongolia for short), the Xinjiang Uygur Autonomous Region (Xinjiang for short), and Sichuan Province, they account for $41.7 \%$ of China's total land area, and constitute the largest terrestrial ecosystem in China(Xie et al., 2001; Xu et al., 2013). Grasslands not only produce feed for animal husbandry, but also fulfill many important ecological service functions, such as carbon fixation and oxygen release, wind break provision and sand fixation, headwater conservation, soil and water conservation, and biodiversity maintenance (Fry et al., 2013).The grass yield of grasslands is both the material basis of grassland ecosystem maintenance and the most direct reflection of grassland status (Xu and Yang, 2009), and it determines the strength of the functions of the grassland ecosystem. Thus, to timely and accurately identify the spatio-temporal distribution of grassland grass yield and grasp its interannual dynamic variation provides an essential scientific basis for determining grazing capacity with reasonable certainty, and has vital theoretical and practical significances for keeping grassland ecological balance and arranging livestock production.

The grass yield of a grassland directly reflects its productivity. The traditional methods of assessing grassland productivity mainly include ground surveys, statistical models (Gao et al., 2009; Li et al., 2003; Liu et al., 2007; Yang et al., 2008), process models (Feng and Zhao, 2011; Goetz et al., 1999; Luo et al., 2012), and parameter models (Li et al., 2007; Zhang et al., 2008). using this technology to estimate the productivity and grass yield of grasslands, and a series of remote sensing estimation models have been put forward(Liu et al., 2020). This technology, when used to estimate the grass yield of grasslands, saves both time and labor, and offers efficient decision-making in grassland management from a macroscopic perspective. 
functions, and other mathematical relationships to construct remote sensing estimation models for grass yield (Bella et al., 2004; Gao et al., 2013; Xu et al., 2007; Yang et al., 2007). For instance, Gao et al. (Gao et al., 2013) investigated the spatial distribution of aboveground and underground biomass in the Xilingol Grassland, Inner Mongolia using MODIS NDVI. Xu et al. (Xu et al., 2008) presented a systematic model that could be used to estimate the grass yield of grasslands on mainland China based on MODIS NDVI and ground samples. Yang et al. (Yang et al., 2009) estimated the aboveground biomass in Tibet using the MODIS enhanced vegetation index (EVI), and analyzed the relationship between aboveground biomass on grasslands and meteorological factors. However, as far as the suitability of a vegetation index to a specific region or environment is concerned, further discussion and experiments are still needed. Some studies hold that NDVI enjoys some advantages when it comes to the remote sensing estimation of grass yield (Ni, 2004). However, the instability and supersaturation of NDVI under different vegetation coverages tend to introduce indeterminate errors into grass yield estimation. In recent years, many scholars have attempted to estimate grass yield with other remote sensing derivative products (such as GPP and MODIS PSNnet). For example, Fu et al. (Fu et al., 2014)combined MODIS GPP and NDVI with calculated vegetation coverage and actual survey data to estimate the grass yield of grasslands in Sichuan Province. Zhao et al. (Zhao et al., 2014) directly constructed a regression model based on MODIS PSNnet and ground survey data, and used it to estimate the grass yield of the Xilingol Grassland.

In addition, as far as remote sensing estimation models for grass yield are concerned, there is also the frequent problem of inconsistency between ground sample data and digital remote sensing images on spatial scales. The main reason is because, on the one hand, sample collection usually adopts a quadrat size of $1 \mathrm{~m} 2$ for the sake of grassland protection. On the other, remote sensing data adopted for large-scale grass yield estimation often have a spatial resolution of 30-1,000 m, and the surface features within each pixel are not singular; the spectral information contained has integrated the spectral characteristics of different vegetation types within different pixels (Zribi et al., 2003). Thus, for the purpose of improving the precision of estimation models, the spatial scale transformation (SST) of remote sensing images and ground samples is highly necessary. 
In sum, studies on the estimation of grass yield using remote sensing technology have

93 achieved numerous significant practical results, however, in-depth research is still needed to solve 94 a series of problems:

(1) There are still controversies around the suitability of various vegetation indices to different environments and the precision of grass yield estimates based on them. In particular, net primary productivity (NPP) is defined as the residual primary productivity of the total organic matter content produced by a green plant within a unit time and unit area after deducting the proportion consumed by the plant itself for autotrophic respiration (Zhou et al., 2020). It is worth exploring whether annual NPP can be adopted as the primary factor for grass yield estimation.

(2) How to solve the problem regarding the effect of the inconsistency between ground samples and remote sensing data on spatial scales on the precision of the remote sensing estimation model for grass yield?

This paper first draws a comparison between NDVI and NPP as grass yield estimation factors, and then proposes the SST for ground samples and remote sensing data based on vegetation coverage on different spatial scales, thus constructing a new remote sensing estimation model for grass yield. Next, it verifies the model using measured ground samples, and performs grass yield estimation for the study area on this basis.

\section{$109 \quad$.2. Study Area}

The area adopted for study in this paper is the Xilingol Grassland, a typical temperate 111 grassland located in central Inner Mongolia, northern China $\left(41^{\circ} 35^{\prime} \sim 46^{\circ} 46^{\prime}\right.$ in north latitude, and

$112111^{\circ} 09^{\prime} \sim 119^{\circ} 58^{\prime}$ in east longitude, as shown in Figure 1). It occupies a total area of 202,580 $\mathrm{km}^{2}$,

$113192,512 \mathrm{~km}^{2}(95.03 \%)$ of which is grassland. The dominant grassland type is natural grassland,

114 which accounts for $97.2 \%$ of total grassland area. The study area has the climatic characteristics of 115 a typical temperate continental semi-arid climate zone, and is cold in the winter and hot in the 116 summer, with mean annual temperatures of $1.3 \sim 4.8^{\circ} \mathrm{C}$ and mean annual precipitation of $150 \sim 400$ $117 \mathrm{~mm}$. Precipitation increases progressively from west to east, and the annual precipitation 118 distribution is uneven ( $70 \%$ concentrated in the period from June to August), with significant 119 interannual variability. 


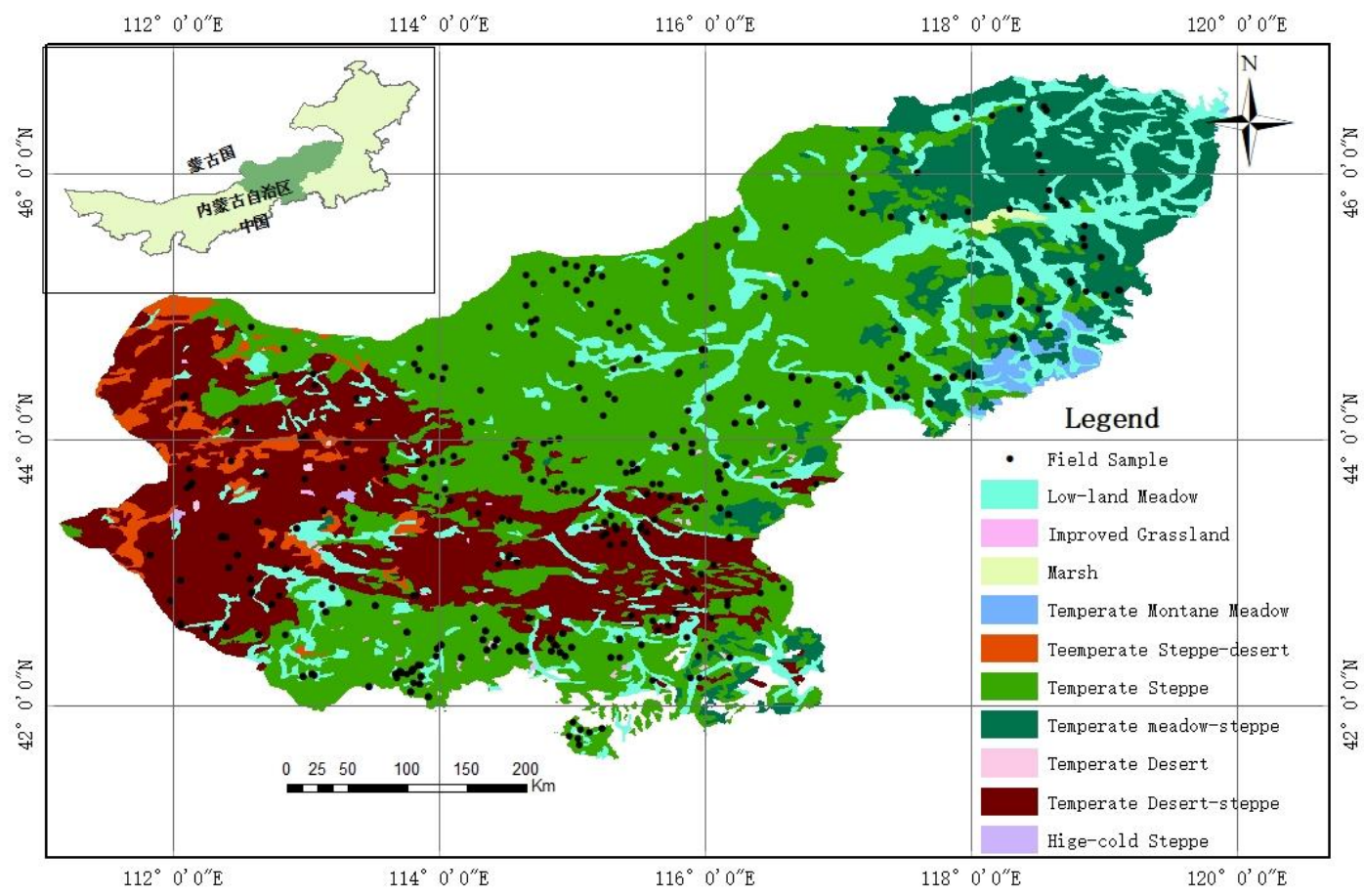

Figure 1. Grassland types and sampling points in the study area.

\section{3. Data and Processing}

\section{$123 \quad 3.1$ Ground survey data}

The ground sample data adopted in this paper were measured ground quadrat data collected by the local grassland authority as entrusted by the Grassland Supervision and Monitoring Center of the Chinese Ministry of Agriculture during July-August (flourishing period for grass), 2013. Fig. 1 shows the spatial distribution of quadrats $(1 \mathrm{~m} \times 1 \mathrm{~m}$ in size $)$. The main sample variables included quadrat longitude and latitude, grassland type, altitude, vegetation type, FGY, measured vegetation coverage (MVC), community height, grazing intensity, and sampling time. The FGY

130 for samples was determined by mowing all the plants within quadrats to ground level and 131 weighing them. Considering that ground sample data quality can substantially affect the estimation precision of models (Matsushita and Tamura, 2002), ground sample data were put

133 through rigorous testing and standardized screening before modeling. After rejecting individual

134 abnormal data based on grassland type and multi-year mean quadrat status, this study ultimately 135 selected a total of 460 sample data (400 randomly selected for modeling, and 60 for precision verification). The quantities and sites of the samples used for modeling and precision verification represented the main grassland types and grass yield in this area. 
The remote sensing data adopted in this paper were mainly derived from the

140 MOD13A1-NDVI and MOD17A3-NPP data products from the official website of the National

141 Aeronautics and Space Administration (NASA). MOD13A is a 16-day synthetic product, with a

142 spatial resolution of $500 \mathrm{~m}$. To effectively eliminate the errors caused by cloud cover, solar zenith

143 angle, and atmosphere and to improve the quality of images (Liu et al., 2016), the NDVI data in

144 the vegetation growth period of the study area (from April 1 to October 31, 2013) were

145 preprocessed using the maximum value composite method (Formula (1)), and marked as ANDVI.

146 MOD17A3-NPP is an annual product, with the same spatial resolution of $500 \mathrm{~m}$ and marked as 147 ANPP

$$
A N D V I=M A X\left(N D V I_{i}\right)
$$

where $A N D V I$ is the annual maximum value of NDVI; $N D V I_{i}$ is the NDVI data from each

150 stage in the study period.

\section{4. Research Methods}

\subsection{Estimation and modification of vegetation coverage}

(1) Estimation of vegetation coverage

It is assumed that each pixel of the study area consists of two parts: that with vegetation coverage and that without (bare land), and the spectral information acquired by remote sensors is a linear combination of two pure components after weighting based on the area ratio. On this basis, the current classical binary pixel method (Ge et al., 2018) is adopted to calculate vegetation coverage from Formula (2) based on ANDVI data. The result is marked as AVC.

$$
A V C_{i}=\frac{A N D V I_{i}-A N D V I_{\min }}{A N D V I_{\max }-A N D V I_{\min }}
$$

Where $i$ is geographical position; AVC is estimated vegetation coverage; ANDVI is the annual maximum value of NDVI; $A N D V I_{\max }$ is the maximum ANDVI of the study area; $A N D V I_{\min }$ is the minimum ANDVI. This paper adopts the ANDVI value corresponding to a cumulative

163 frequency of $95 \%$ as $A N D V I_{\max }$, and that corresponding to a cumulative frequency of $5 \%$ as $164 \quad A N D V I_{\text {min }}$.

165 (2) Modification of vegetation coverage 
MVC is usually performed with discrete points based on the design scheme, while subsequent grass yield estimation is conducted pixel by pixel. Assuming that the vegetation coverage of the pixel where a sample is located is uniform and consistent with the measured vegetation coverage of the sample, to obtain the measured vegetation coverage of the entire study area, this paper proposes to modify AVC using MVC, as described below:

(1) Exact AVC based on the position of the quadrat, and perform margin calculation between MVC and AVC to obtain residual $\alpha$ (Formula (3)).

$$
\alpha=M V C-A V C
$$

(2) Provide Kriging interpolation for the calculated residual, modify AVC using image operation (Formula (4)), and mark it as RAVC.

$$
R A V C=A V C+\alpha
$$

\subsection{Modification of NPP}

Some studies have pointed out that the vegetation index (VI) is highly correlated with light use efficiency (LUE) and fraction of photosynthetically active radiation (FPAR) (Inoue et al., 2008; Viña and Gitelson, 2005). Related literature has confirmed that VI is a reliable reflection of LUE and FPAR, and that there is a high correlation between GPP/NPP and $\mathrm{VI}^{2} \times$ PAR (photosynthetically active radiation) (Gitelson et al., 2012; Wu et al., 2010). Based on the above parameter relationships, this paper introduces ANPP_NDVI (Formula (5)) to express ANPP modified according to the above principle.

$$
A N P P_{\mathrm{NDVI}}=A N P P \times A N D V I^{2}
$$

\subsection{SST of grass yield data}

According to a comparison between FGY and ANPP, FGY comes from measured ground samples, with a spatial scale of $1 \mathrm{~m}$, while ANPP is the MOD17A3-NPP data product with a spatial resolution of $500 \mathrm{~m}$. For this reason, directly adopting ANPP for FGY estimation introduces unknown factors due to the inconsistency between spatial scales and lowers the fitting precision of the model.

Similarly, a comparison between AVC and RAVC reveals that AVC is calculated using ANDVI according to the binary pixel method, with a spatial scale of $500 \mathrm{~m}$, whereas RAVC assumes that the vegetation coverage of each pixel is uniform and consistent with the measured 
vegetation coverage of the sample. RAVC can be regarded by default as the vegetation coverage of the sample, with a spatial scale of $1 \mathrm{~m}$. Assuming the coefficient of SST between them as $k$, the value of $k$ can be calculated from the ratio of AVC to RAVC.

Assuming that there is a proportional relationship between FGY and vegetation coverage, the coefficient of SST can also be regarded as the ratio of the grass yield per unit with a spatial scale of $500 \mathrm{~m}\left(\mathrm{FGY}_{500}\right)$ to the grass yield per unit with a ground measured spatial scale of $1 \mathrm{~m}$ (FGY) (Formula (6)).

$$
\frac{A V C}{R A V C}=k=\frac{A F Y_{500}}{A F Y}
$$

As can be seen from the above assumptions and analysis, the SST between FGY500 and FGY can be calculated based on AVC and RAVC.

\subsection{Precision verification}

To verify the precision of different remote sensing estimation models for FGY, this paper selects the commonly-used relative estimation error (REE) for precision evaluation. The formula is given below:

$$
R E E=\sqrt{\frac{\sum\left[\left(y_{i}-y_{i}^{\prime}\right) / y_{i}^{\prime}\right]^{2}}{N}}
$$

where $y_{i}$ is the survey data; $y i^{\prime}$ is the estimate from the regression model; $N$ is the number of validation points.

To evaluate the total FGYs estimated by different models, this paper adopts relative estimation precision for quantitative analysis according to the following formula:

$$
R S P_{i j}=1-\frac{\vartheta_{s i}-\vartheta_{s j}}{\vartheta_{s i}}
$$

where $R S P_{i j}$ is the estimation precision of model $j$ relative to model $i$; $\vartheta_{s i}$ is the total FGY of the entire study area estimated by model $i$; $\vartheta_{s j}$ is FGY estimated by model $j$.

\section{Results and Discussion}

\subsection{Comparison of ANDVI and ANPP as grass yield estimation factors}

As pointed out by related literature, in the remote sensing estimation of grass yield, NDVI produces desirable results as an estimation factor (Liu et al., 2020); however, due to its 
221 supersaturation, it tends to underestimate grass yield in high-yield regions. In view of this problem,

222 this paper proposes to adopt NPP, instead of NDVI, as the primary factor for grass yield 223 estimation. Meanwhile, scatter diagrams were constructed using ANDVI/ANPP and FGY, and 224 fitting was performed using linear, power, and exponential functions to construct remote sensing 225 estimation models for FGY. In addition, measured ground samples were adopted for precision 226 verification and evaluation, as detailed in Figure 2, Figure 3 and Table 1.

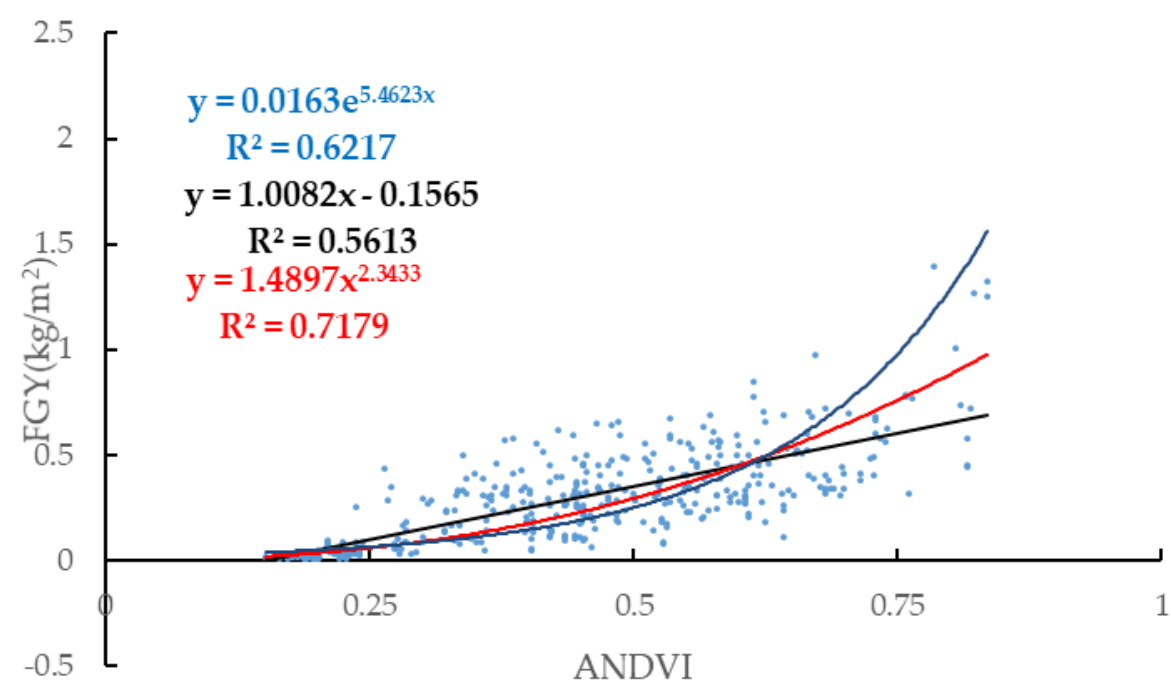

Figure 2. Scatter diagrams constructed using ANDVI and FGY.

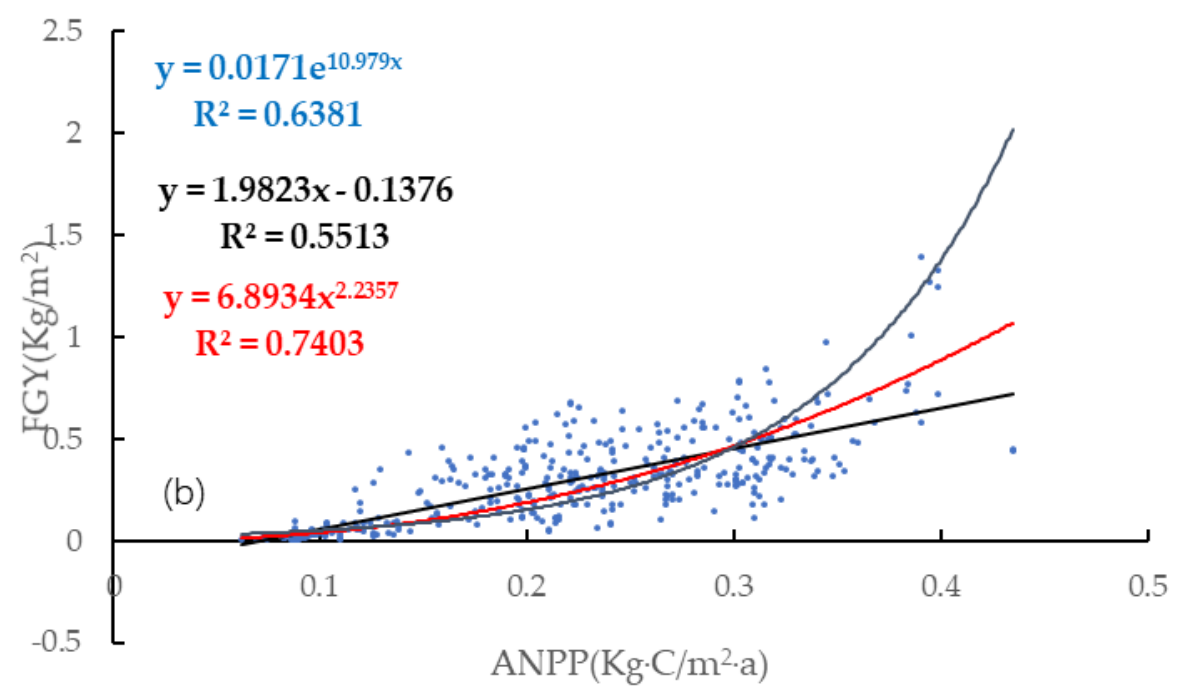

Figure 3. Scatter diagrams constructed using ANPP and FGY. 
Table 1. Comparison of FGY estimation models based on ANDVI and ANPP.

\begin{tabular}{ccccc}
\hline Estimate main factors & Function & Formula & $\mathbf{R}^{\mathbf{2}}$ & REE \\
\hline \multirow{3}{*}{ ANDVI } & linear function & $\mathrm{y}=1.0082 \mathrm{x}-0.1565$ & 0.56 & $42.52 \%$ \\
& exponential function & $\mathrm{y}=0.0163 \mathrm{e}^{5.4623 \mathrm{x}}$ & 0.62 & $55.94 \%$ \\
& linear function & $\mathrm{y}=1.0082 \mathrm{x}-0.1565$ & 0.56 & $42.52 \%$ \\
& linear function & $\mathrm{y}=1.9823 \mathrm{x}-0.1376$ & 0.55 & $39.11 \%$ \\
ANPP & exponential function & $\mathrm{y}=0.0171 \mathrm{e}^{10.979 \mathrm{x}}$ & 0.64 & $44.76 \%$ \\
& power function & $\mathrm{y}=6.8934 \mathrm{x}^{2.2357}$ & 0.74 & $36.67 \%$ \\
\hline
\end{tabular}

Compared with the three fitting functions based on ANDVI, all of the three fitting functions

236 based on ANPP, except for the linear function, had a greater $\mathrm{R}^{2}$ value. When measured ground 237 samples were used for testing, it was found that, regardless of the specific function used for fitting 238 the estimation model, the precision of ANPP-based estimation models was uniformly superior to 239 that of ANDVI-based estimation models. Thus, adopting ANPP as the main estimation factor of 240 FGY has clear advantages. Meanwhile, through comparing the models constructed using the three 241 functions, it was found that the exponential function had the least desirable effect, so subsequently 242 it would not be used for fitted regression.

\section{5.2 SST-based FGY estimation model}

244 The above results indicated that there was a high correlation between AFY500 and ANPP, 245 which agreed with a mathematic function (Formula (9)). In combination with Formula (6), it can 246 be held that, theoretically, there is a high correlation between $A F Y \times A V C$ and $A N P P \times R A V C$.

247 To verify the above assumptions and deductions, this paper constructed scatter diagrams with $248 A F Y \times A V C$ and $A N P P \times R A V C$, and used linear and power functions for fitted regression, as shown 249 in Figure 4. Clearly, regardless of the linear or power function used, $\mathrm{R}^{2}$ always improved. 250 However, the intercept of the linearly fitted regression model was negative, and, when the value of $251 A N P P \times R A V C$ was very small, it resulted in a negative estimate of FGY. 


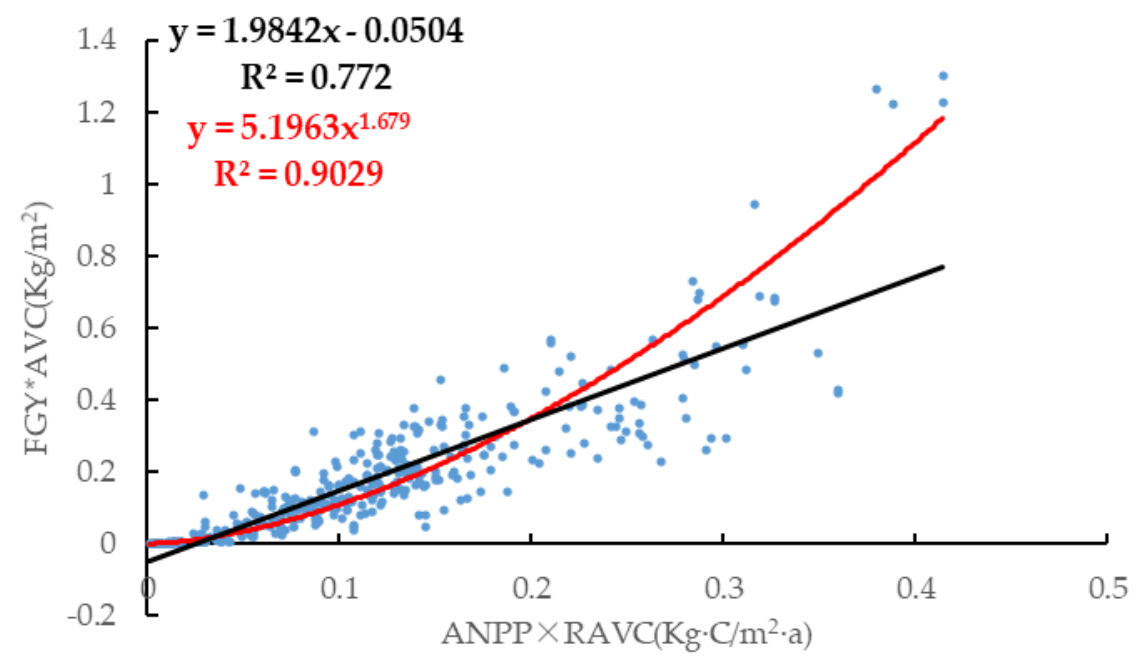

Figure 4. Scatter diagram constructed using AFY $\times A V C$ and $A N P P \times R A V C$.

For the purpose of further improving the reliability and precision of remote sensing 255 estimation models for FGY, $A N P P_{N D V I}$ was adopted as a substitute for $A N P P$, and scatter diagrams 256 were constructed using $A F Y \times A V C$ and $A N P P_{N D V I} \times R A V C$ (Figure5). As can be seen from Figure 5,

257 the correlations between the two became even more obvious $\left(R^{2}\right.$ linear $=0.81, R^{2}$ power $\left.=0.93\right)$.

258 According to a comparison between Figure 4 and Figure 5, a positive intercept of the linearly

259 fitted regression model helped effectively avoid the possibility of negative grass yield when the 260 ANPP value was small. When measured ground samples data were adopted for precision 261 verification (Table 2), the REE of linear function was $18.16 \%$, while the power function was $26218.35 \%$. The fitted regression models constructed using the two functions had roughly the same 263 estimation precision.

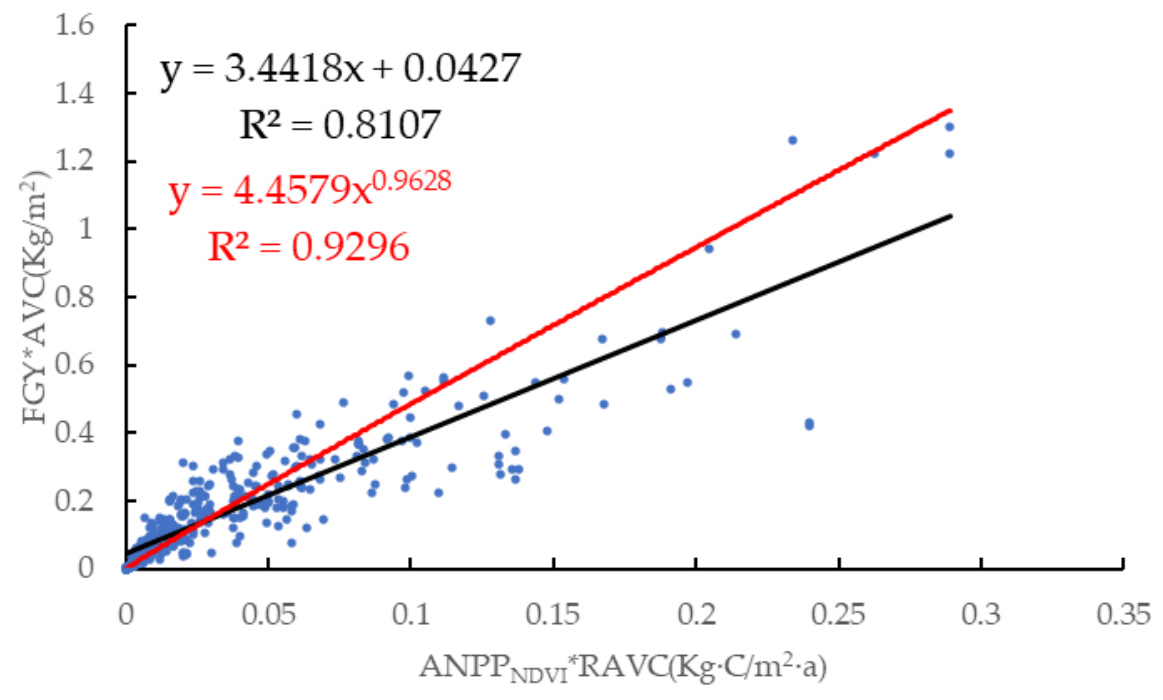


Figure 5. Scatter diagram constructed using $A F Y \times A V C$ and $A N P P_{N D V I} \times R A V C$.

Table 2. Comparison of multi-factor composite remote sensing estimation models for grass yield.

\begin{tabular}{cccc}
\hline Function & Formula & $\mathbf{R}^{\mathbf{2}}$ & REE \\
\hline Linear function & $\mathrm{y}=3.4418 \mathrm{x}+0.0427$ & 0.81 & $18.16 \%$ \\
Power function & $\mathrm{y}=4.4579 \mathrm{x}^{0.9628}$ & 0.93 & $18.35 \%$ \\
\hline
\end{tabular}

\subsection{Estimation of the grass yield of the study area}

268 The SST-based fitted regression formulae constructed using linear and power functions were

269 employed to estimate the grass yield for the study area, as shown in Figure 6 and Figure 7.

270 According to the statistical results, when the fitted regression models constructed using linear and

271 power functions were used to estimate the total FGY of the grassland in the study area, the

272 respective results were $8.777 \times 10^{10} \mathrm{~kg}$ and $8.583 \times 10^{10} \mathrm{~kg}$, so there was no significant gap. Relative

273 to the power function fitted model, the linear function fitted model had a relative precision of

$27497.8 \%$; relative to the linear function fitted model, the power function fitted model had a relative

275 precision of $97.7 \%$.

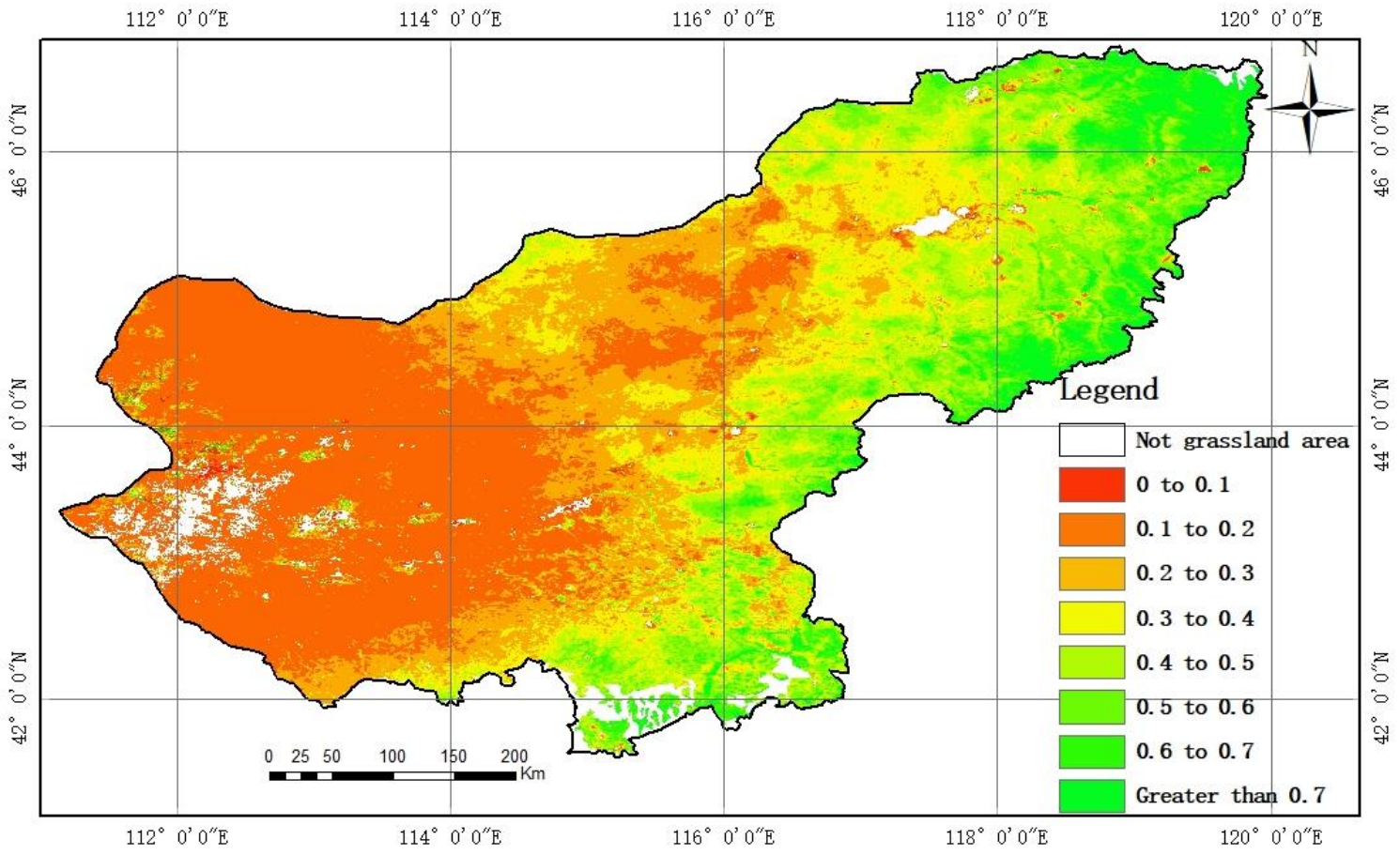

Figure 6. Results estimated by the linear function fitted model. 


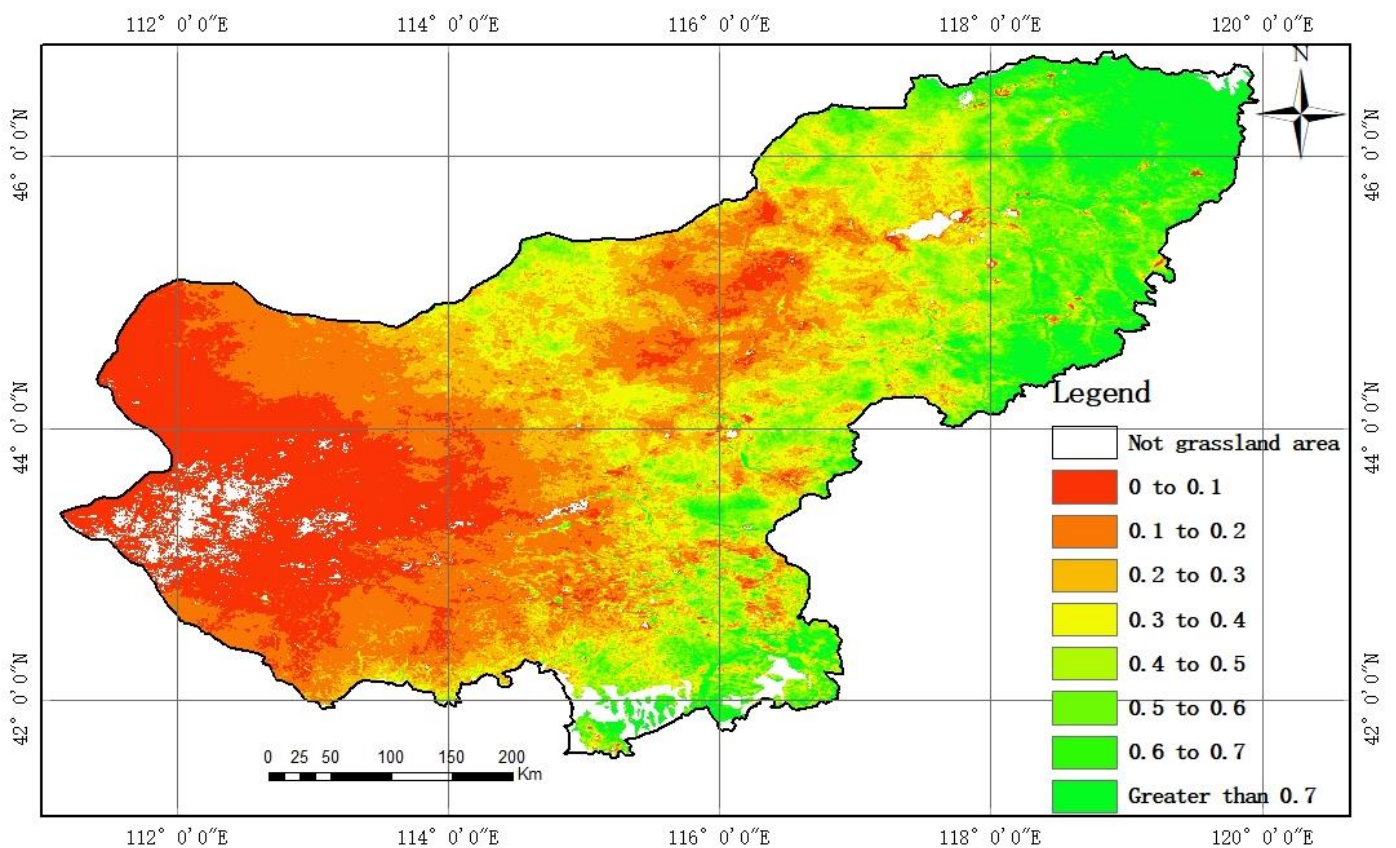

Figure 7. Results estimated by the power function fitted model.

A comparison between Figure 6 and Figure 7 revealed that, spatially, the two models had

281 similar overall trends for FGY per unit; however, significant differences in spatial distribution 282 could be observed. As indicated by the statistical results (Table 3), in the west and middle of the 283 study area, the area with a FGY per unit of less than $0.1 \mathrm{~kg} / \mathrm{m}^{2}$ estimated by the power function 284 fitted model was far greater than that estimated by the linear function fitted model. In the east and 285 south of the study area, the area with a FGY per unit of greater than $0.7 \mathrm{~kg} / \mathrm{m}^{2}$ estimated by the 286 power function fitted model was also far greater than that estimated by the linear function fitted model. However, due to the lack of data on large-scale regional FGY, it was difficult to evaluate 288 the advantages and disadvantages of the two models. In follow-up research, the coverage of 289 ground samples will be expanded to further explore this issue.

Table 3. Statistics on grass yield per unit.

\begin{tabular}{ccc}
\hline $\begin{array}{c}\text { FGY per unit } \\
\left(\mathbf{k g} / \mathbf{m}^{\mathbf{2}}\right)\end{array}$ & Linear function model & $\begin{array}{c}\text { Power function } \\
\text { model }\end{array}$ \\
\hline less than 0.1 & $0.12 \%$ & $18.95 \%$ \\
$0.1-0.2$ & $33.68 \%$ & $20.29 \%$ \\
$0.2-0.3$ & $18.97 \%$ & $16.09 \%$ \\
$0.3-0.4$ & $14.93 \%$ & $13.82 \%$ \\
$0.4-0.5$ & $13.80 \%$ & $9.83 \%$ \\
$0.5-0.6$ & $9.29 \%$ & $7.58 \%$ \\
$0.6-0.7$ & $4.68 \%$ & $5.11 \%$ \\
greater than 0.7 & $4.54 \%$ & $8.34 \%$ \\
\hline
\end{tabular}




\section{Conclusion}

The global NPP product provided by MODIS tended to compromise grass yield estimation precision due to the uncertainty of self-inversion. However, as indicated by a comparison between remote sensing estimation models adopting NPP and NDVI as the main estimation factor for FGY, NPP produced more desirable results. Given the failure to improve estimation precision due to the inconsistency between remote sensing data and ground samples on spatial scales, SST was performed using the vegetation coverage before and after modification, and a SST-based FGY estimation model was proposed. As demonstrated by the results of the case study based on the grassland in Xilingol League, the model effectively improved estimation precision.

The SST-based fitted regression models constructed using linear and power functions were employed to estimate the total FGY for the entire study area, resulting in respective estimates of $8.777 \times 10^{10} \mathrm{~kg}$ and $8.583 \times 10^{10} \mathrm{~kg}$. Therefore, the two models obtained roughly the same estimate, and their spatial distribution trends were also consistent. However, there were significant differences in the spatial distribution of FGY per unit, which calls for follow-up research. Based on this comprehensive analysis, the research group draws the conclusion that when using the MODIS-NPP data product as the main variable, the SST-based FGY estimation model can be used to estimate regional grass yield.

\section{Acknowledgments}

This research was partially supported by Natural Science Foundation of China (No. 42071246) and Natural Fund Commission of Hebei Province (No. E2020402006).

\section{References}

Bella, D. et al., 2004. Remote sensing capabilities to estimate pasture production in France. International Journal of Remote Sensing, 25(23): 5359-5372.

Feng, X.M. and Zhao, Y.S., 2011. Grazing intensity monitoring in Northern China steppe: Integrating CENTURY model and MODIS data. Ecological Indicators, 11(1): 175-182.

Fry, E.L. et al., 2013. Plant functional group composition modifies the effects of precipitation change on grassland ecosystem function. PloS one, 8(2). 

$102-108$.

Gao, H., Pan, X.B. and Fu, Y., 2009. Influence of climate change on potential climate productivity in grassland of

Gao, T. et al., 2013. Spatio-temporal variation in vegetation biomass and its relationships with climate factors in the Xilingol grasslands, Northern China. PLoS One, 8(12).

Gao, T. et al., 2013. Using MODIS time series data to estimate aboveground biomass and its spatio-temporal

330 Ge, J. et al., 2018. Modeling alpine grassland cover based on MODIS data and support vector machine regression

331 in the headwater region of the Huanghe River, China. Remote sensing of environment, 218: 162-173.

332 Gitelson, A.A. et al., 2012. Remote estimation of crop gross primary production with Landsat data. Remote 333 Sensing of Environment, 121: 404-414.

334 Goetz, S.J., Prince, S.D., Goward, S.N., Thawley, M.M. and Small, J., 1999. Satellite remote sensing of primary 335 production: an improved production efficiency modeling approach. Ecological Modelling, 122(3): 239-255. Inoue, Y., Peñuelas, J., Miyata, A. and Mano, M., 2008. Normalized difference spectral indices for estimating photosynthetic efficiency and capacity at a canopy scale derived from hyperspectral and $\mathrm{CO} 2$ flux measurements in rice. Remote Sensing of Environment, 112(1): 156-172.

339 Li, G., Xin, X.P., Wang, D.L. and Shi, R.X., 2007. Application of improved CASA model in productivity 340 evaluation of grassland in Inner Mongolia. Chinese Journal of Ecology, 26(12): 2100-2106.

341 Li, Z., Liu, Z. and Chen, Z., 2003. The effects of climate changes on the productivity in the Inner Mongolia steppe 342 of China. Acta Prataculturae Sinica, 12(1): 4-10.

343 Liu, A.J., Wang, J.J. and Han, J.G., 2007. Study on method of estimating net primary production of rangeland by 344 remote sensing-a case study of Xilingol grassland. Chinese Journal of Grassland, 29: 31-37.

345 Liu, H. et al., 2016. The Spatiotemporal Variation of Drought in the Beijing-Tianjin-Hebei Metropolitan Region 346 (BTHMR) Based on the Modified TVDI. Sustainability, 8(12): 1327.

347 Liu, J. et al., 2020. Modeling grass yields in Qinghai Province, China, based on MODIS NDVI data—an empirical 
349 Luo, G. et al., 2012. Moderate grazing can promote aboveground primary production of grassland under water stress. Ecological Complexity, 11: 126-136.

351 Matsushita, B. and Tamura, M., 2002. Integrating remotely sensed data with an ecosystem model to estimate net 352 primary productivity in East Asia. Remote Sensing of Environment, 81(1): 58-66.

353 Ni, J., 2004. Estimating net primary productivity of grasslands from field biomass measurements in temperate 354 northern China. Plant Ecology, 174(2): 217-234.

355 Suttie, J.M., Reynolds, S.G. and Batello, C., 2005. Grasslands of the World, 34. Food \& Agriculture Org.

356 Viña, A. and Gitelson, A.A., 2005. New developments in the remote estimation of the fraction of absorbed photosynthetically active radiation in crops. Geophysical Research Letters, 32(17).

358 Wu, C., Han, X., Ni, J., Niu, Z. and Huang, W., 2010. Estimation of gross primary production in wheat from in 359 situ measurements. International Journal of Applied Earth Observation and Geoinformation, 12(3): 183-189.

360 Xie, G., Zhang, Y., Lu, C., Zheng, D. and Cheng, S., 2001. Study on valuation of rangeland ecosystem services of 361 China. Journal of Natural Resources, 16(1): 47-53.

$362 \mathrm{Xu}$, B. et al., 2007. Remote sensing monitoring upon the grass production in China. Acta Ecologica Sinica, 27(2): $363 \quad 405-413$.

$364 \mathrm{Xu}$, B. et al., 2008. MODIS-based remote sensing monitoring of grass production in China. International Journal 365 of Remote Sensing, 29(17-18): 5313-5327.

$366 \mathrm{Xu}$, B. et al., 2013. MODIS-based remote-sensing monitoring of the spatiotemporal patterns of China's grassland 367 vegetation growth. International journal of remote sensing, 34(11): 3867-3878.

368 Xu, B. and Yang, X., 2009. Calculation of grass production and balance of livestock carrying capacity in rangeland 369 region of Northeast China. Geographical Research, 28(2): 402-408.

370 Yang, X., Xu, B., Zhu, X., Tao, W. and Liu, T., 2007. Models of grass production based on remote sensing 371 monitoring in northern agro-grazing ecotone [J]. Geographical Research, 2.

372 Yang, Y.H., Fang, J.Y., Pan, Y.D. and Ji, C.J., 2009. Aboveground biomass in Tibetan grasslands. Journal of Arid 373 Environments, 73(1): 91-95.

374 Yang, Z.L., Du, W.X., Hou, Q., Li, X. and Wang, B., 2008. Regional analysis of climate change in the east of 375 Inner Mongolia and its potential productivity of grassland. Chin. J. Grassl, 30: 62-66. 
376 Zhang, F., Zhou, G.S. and Wang, Y.H., 2008. Dynamics simulation of net primary productivity by a satellite

377 data-driven CASA model in Inner Mongolian typical steppe. China. J. Plant Ecol, 32(4): 786-797.

378 Zhao, F. et al., 2014. Remote Sensing Estimates of Grassland Aboveground Biomass Based on MODIS Net

379 Primary Productivity (NPP): A Case Study in the Xilingol Grassland of Northern China. Remote Sensing, 6(6):

$380 \quad 5368-5386$.

381 Zhou, W., Li, J. and Yue, T., 2020. The Variation of Landscape and NPP of Main Pastoral Grasslands in China.

382 Springer, pp. 83-104.

383 Zribi, M. et al., 2003. Derivation of wild vegetation cover density in semi-arid regions: ERS2/SAR evaluation.

384 International Journal of Remote Sensing, 24(6): 1335-1352.

385

386 


\section{Table captions}

389 Table 1 Comparison of FGY estimation models based on ANDVI and ANPP

390 Table 2 Comparison of multi-factor composite remote sensing estimation models for

391 grass yield

392 Table 3 Statistics on grass yield per unit

393 
Table 1. Comparison of FGY estimation models based on ANDVI and ANPP.

\begin{tabular}{ccccc}
\hline Estimate main factors & Function & Formula & $\mathbf{R}^{\mathbf{2}}$ & REE \\
\hline \multirow{3}{*}{ ANDVI } & linear function & $\mathrm{y}=1.0082 \mathrm{x}-0.1565$ & 0.56 & $42.52 \%$ \\
& exponential function & $\mathrm{y}=0.0163 \mathrm{e}^{5.4623 \mathrm{x}}$ & 0.62 & $55.94 \%$ \\
& linear function & $\mathrm{y}=1.0082 \mathrm{x}-0.1565$ & 0.56 & $42.52 \%$ \\
& linear function & $\mathrm{y}=1.9823 \mathrm{x}-0.1376$ & 0.55 & $39.11 \%$ \\
ANPP & exponential function & $\mathrm{y}=0.0171 \mathrm{e}^{10.979 \mathrm{x}}$ & 0.64 & $44.76 \%$ \\
& power function & $\mathrm{y}=6.8934 \mathrm{x}^{2.2357}$ & 0.74 & $36.67 \%$ \\
\hline
\end{tabular}

396

397 
Table 2. Comparison of multi-factor composite remote sensing estimation models for grass yield.

\begin{tabular}{cccc}
\hline Function & Formula & $\mathbf{R}^{2}$ & REE \\
\hline Linear function & $\mathrm{y}=3.4418 \mathrm{x}+0.0427$ & 0.81 & $18.16 \%$ \\
Power function & $\mathrm{y}=4.4579 \mathrm{x}^{0.9628}$ & 0.93 & $18.35 \%$ \\
\hline
\end{tabular}

400

401 
Table 3. Statistics on grass yield per unit.

\begin{tabular}{ccc}
\hline $\begin{array}{c}\text { FGY per unit } \\
\left(\mathbf{k g} / \mathbf{m}^{\mathbf{2}}\right)\end{array}$ & Linear function model & $\begin{array}{c}\text { Power function } \\
\text { model }\end{array}$ \\
\hline less than 0.1 & $0.12 \%$ & $18.95 \%$ \\
$0.1-0.2$ & $33.68 \%$ & $20.29 \%$ \\
$0.2-0.3$ & $18.97 \%$ & $16.09 \%$ \\
$0.3-0.4$ & $14.93 \%$ & $13.82 \%$ \\
$0.4-0.5$ & $13.80 \%$ & $9.83 \%$ \\
$0.5-0.6$ & $9.29 \%$ & $7.58 \%$ \\
$0.6-0.7$ & $4.68 \%$ & $5.11 \%$ \\
greater than 0.7 & $4.54 \%$ & $8.34 \%$ \\
\hline
\end{tabular}

404

405 


\section{$407 \quad$ Figure captions}

408 Figure 1. Grassland types and sampling points in the study area.

409 Figure 2. Scatter diagrams constructed using ANDVI and FGY.

410 Figure 3. Scatter diagrams constructed using ANPP and FGY.

411 Figure 4. Scatter diagram constructed using $A F Y \times A V C$ and $A N P P \times R A V C$.

412 Figure 5. Scatter diagram constructed using $A F Y \times A V C$ and $A N P P_{N D V I} \times R A V C$.

413 Figure 6. Results estimated by the linear function fitted model.

414 Figure 7. Results estimated by the power function fitted model.

415 
416

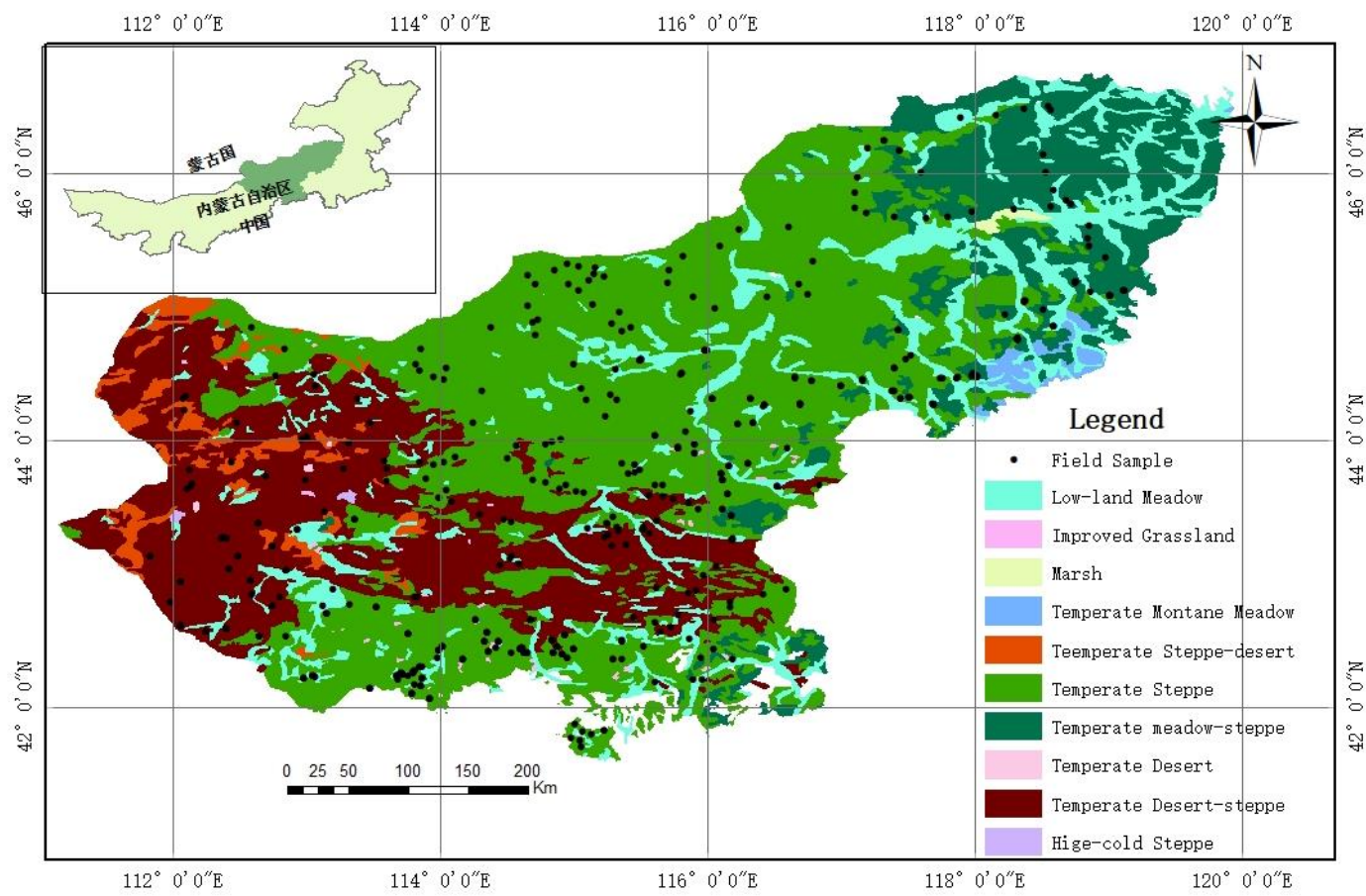

418

Figure 1. Grassland types and sampling points in the study area. 


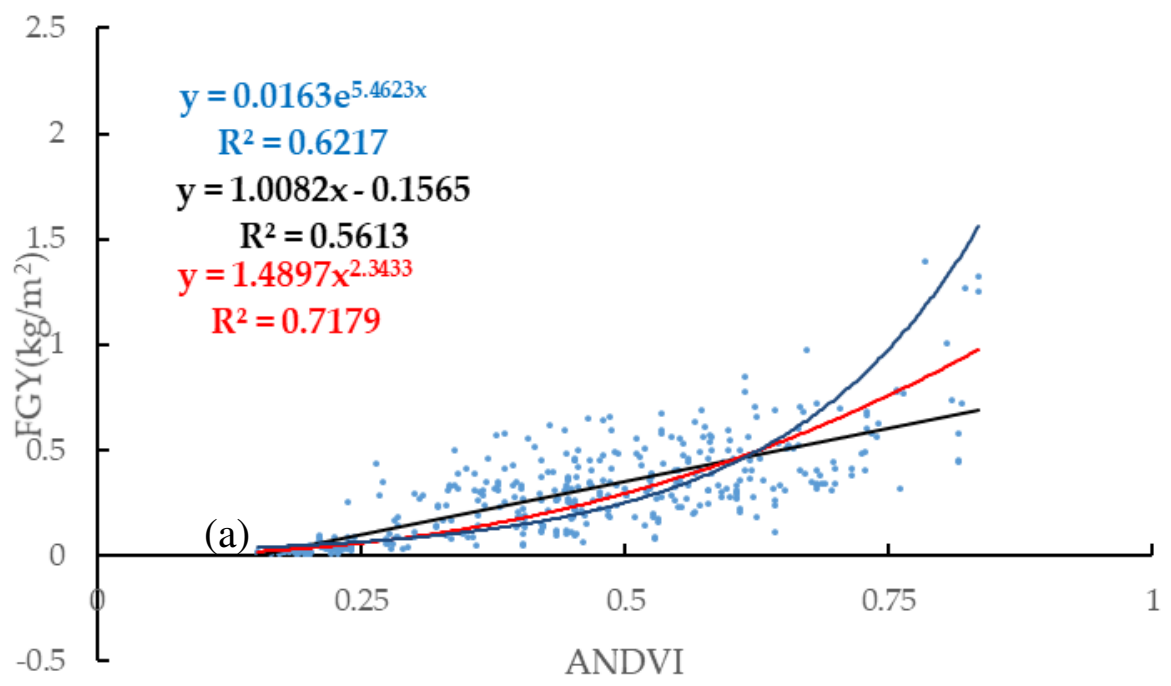




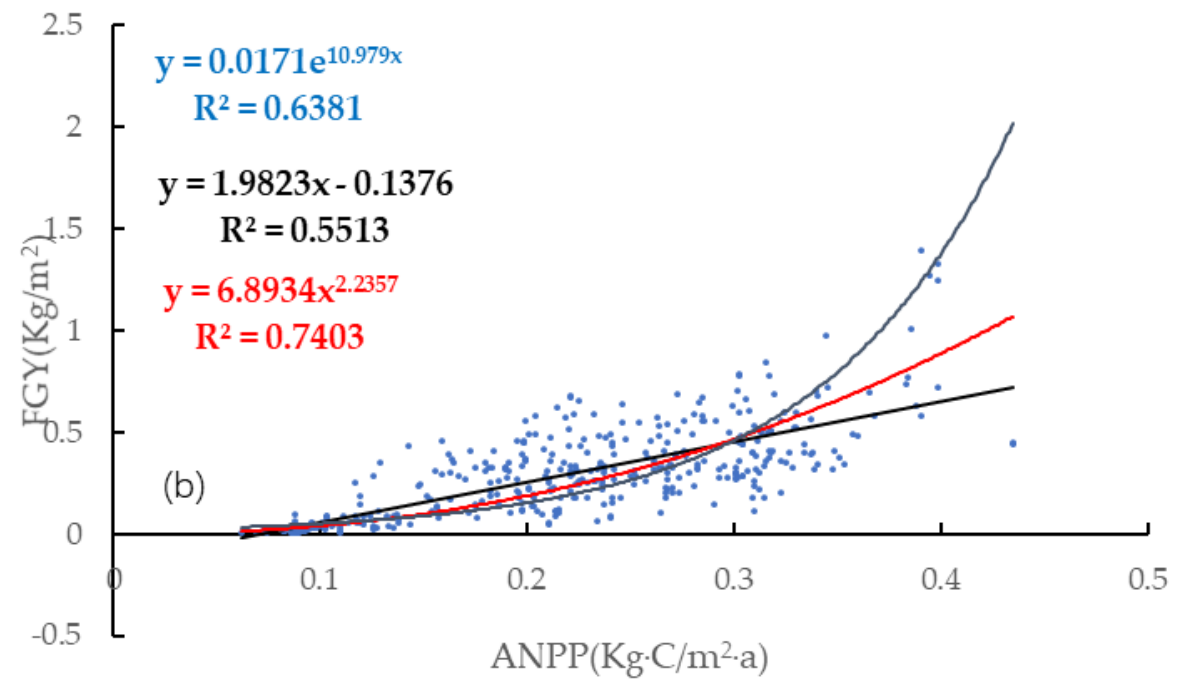




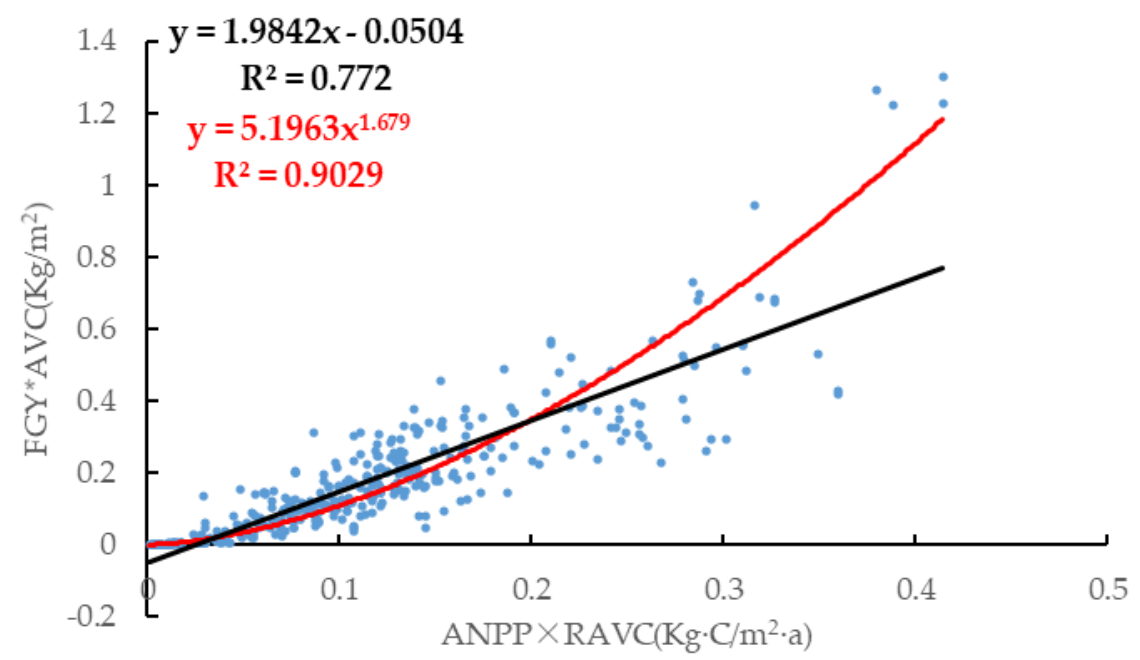

Figure 4. Scatter diagram constructed using $A F Y \times A V C$ and $A N P P \times R A V C$. 
433

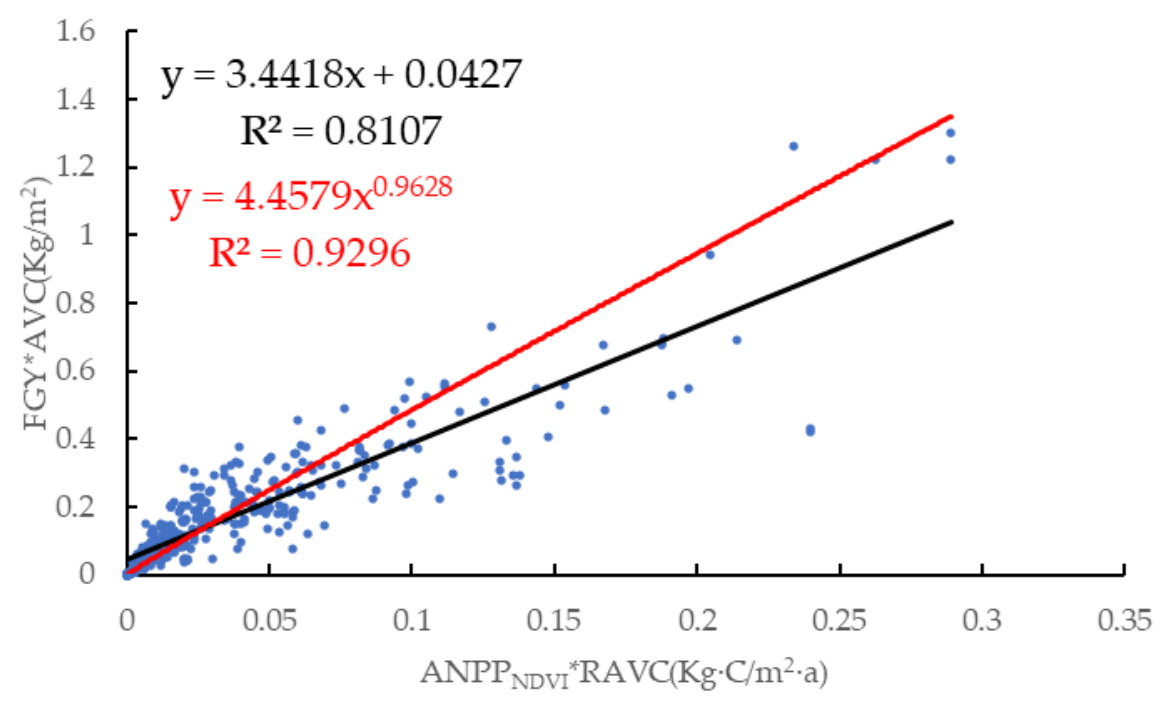

Figure 5. Scatter diagram constructed using $A F Y \times A V C$ and $A N P P_{N D V I \times} \times R A V C$.

436 


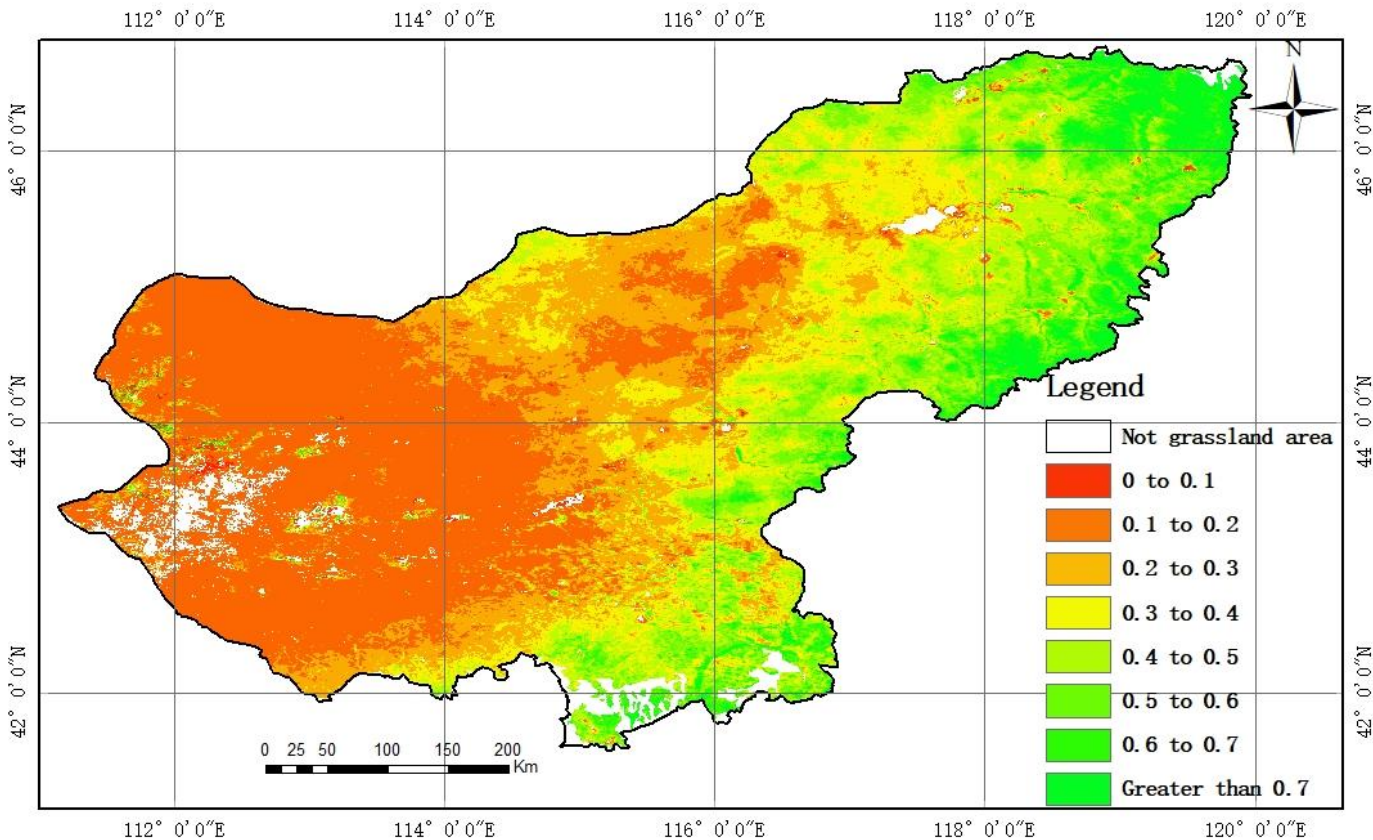

Figure 6. Results estimated by the linear function fitted model. 
441

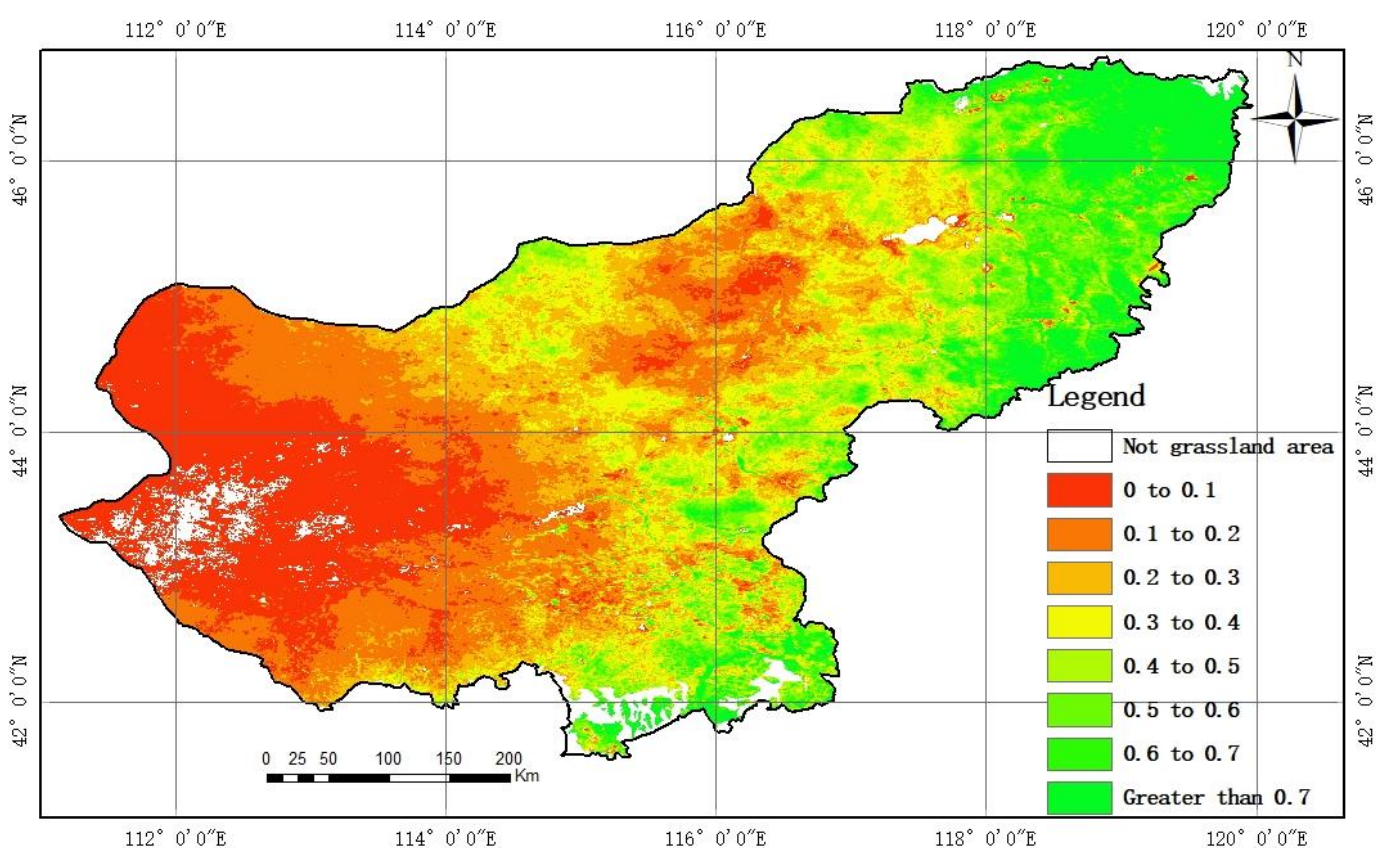

442

Figure 7. Results estimated by the power function fitted model.

444 


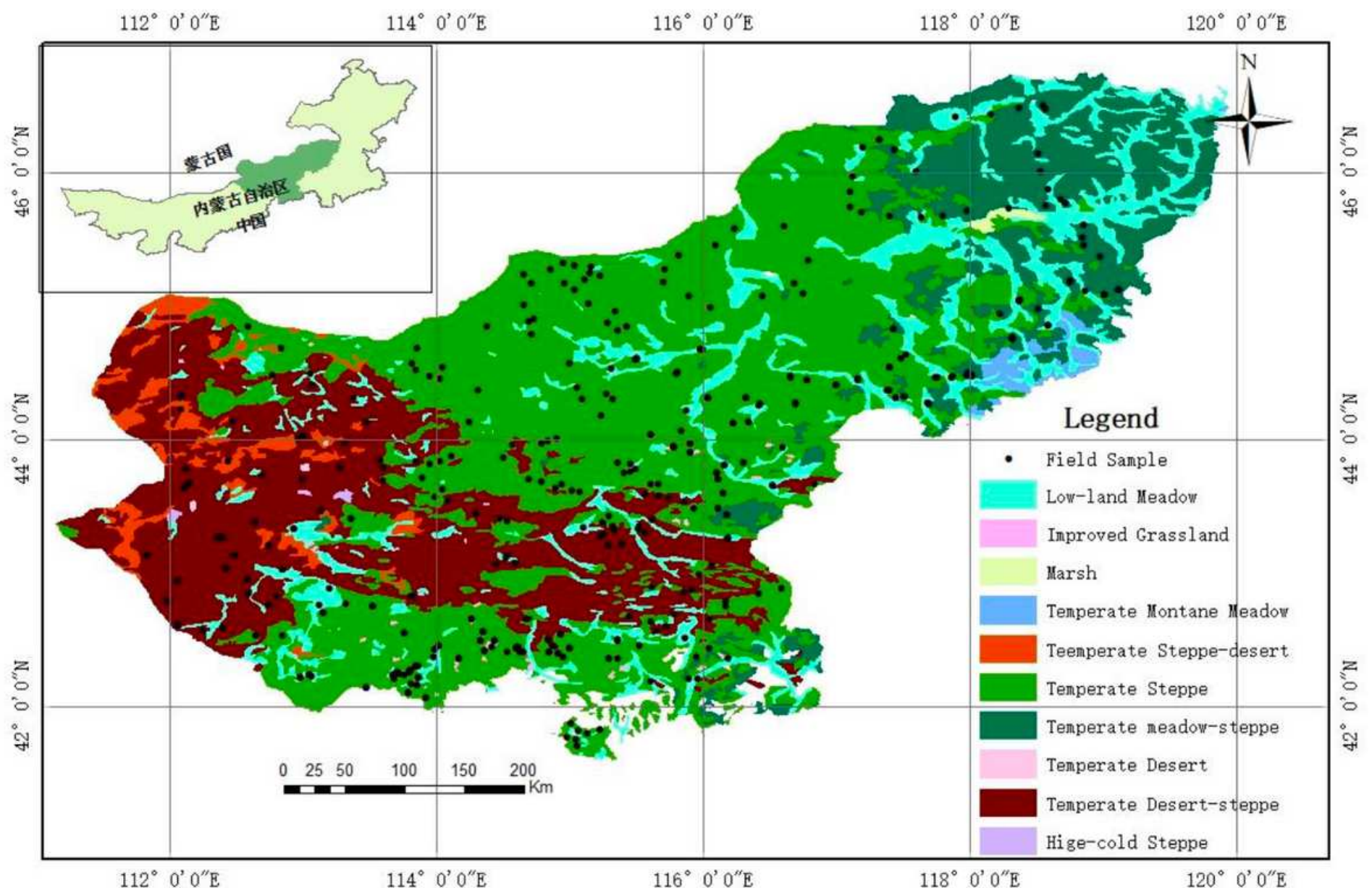

\section{Figure 1}

Grassland types and sampling points in the study area. Note: The designations employed and the presentation of the material on this map do not imply the expression of any opinion whatsoever on the part of Research Square concerning the legal status of any country, territory, city or area or of its authorities, or concerning the delimitation of its frontiers or boundaries. This map has been provided by the authors. 


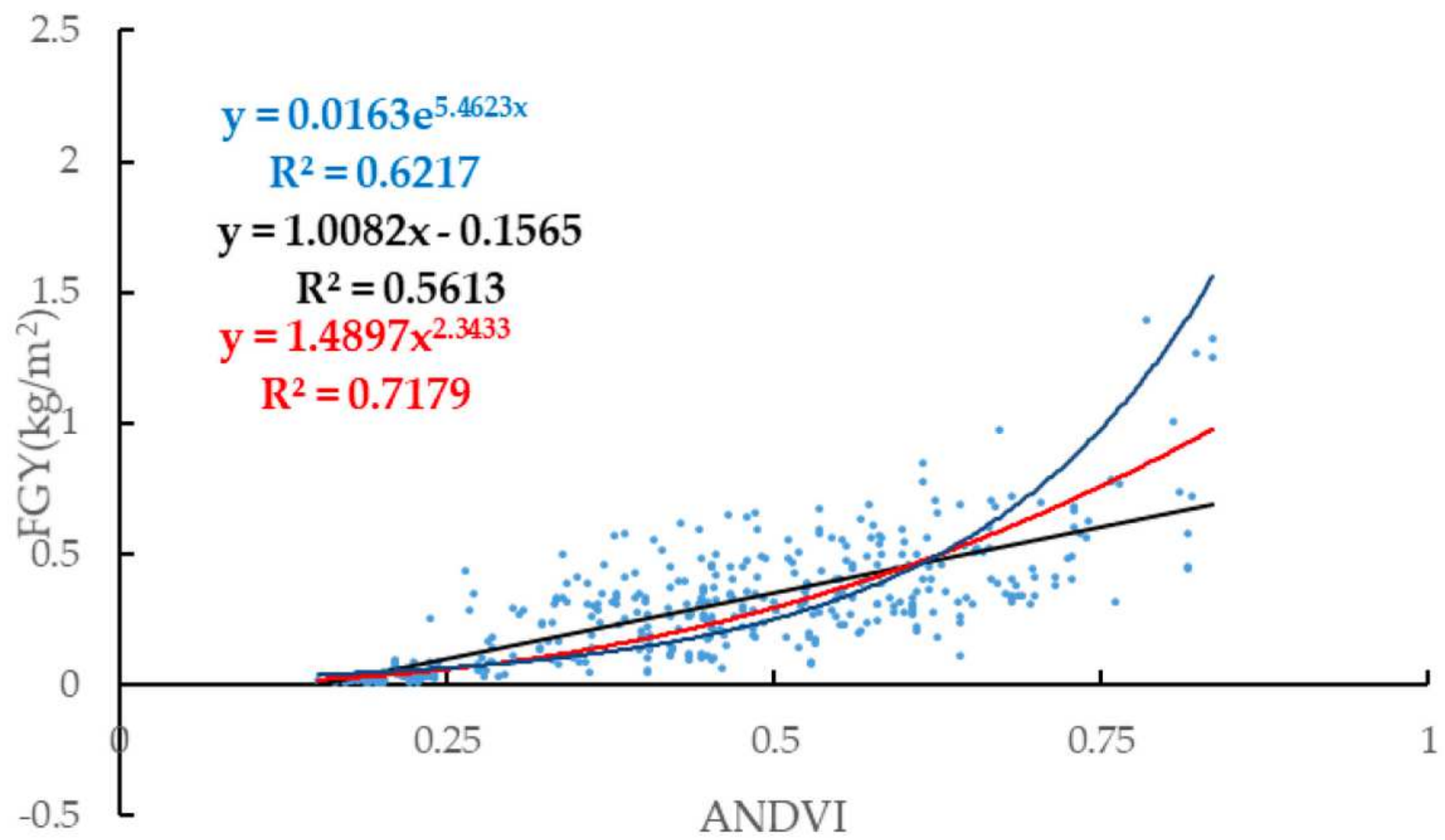

Figure 2

Scatter diagrams constructed using ANDVI and FGY. 


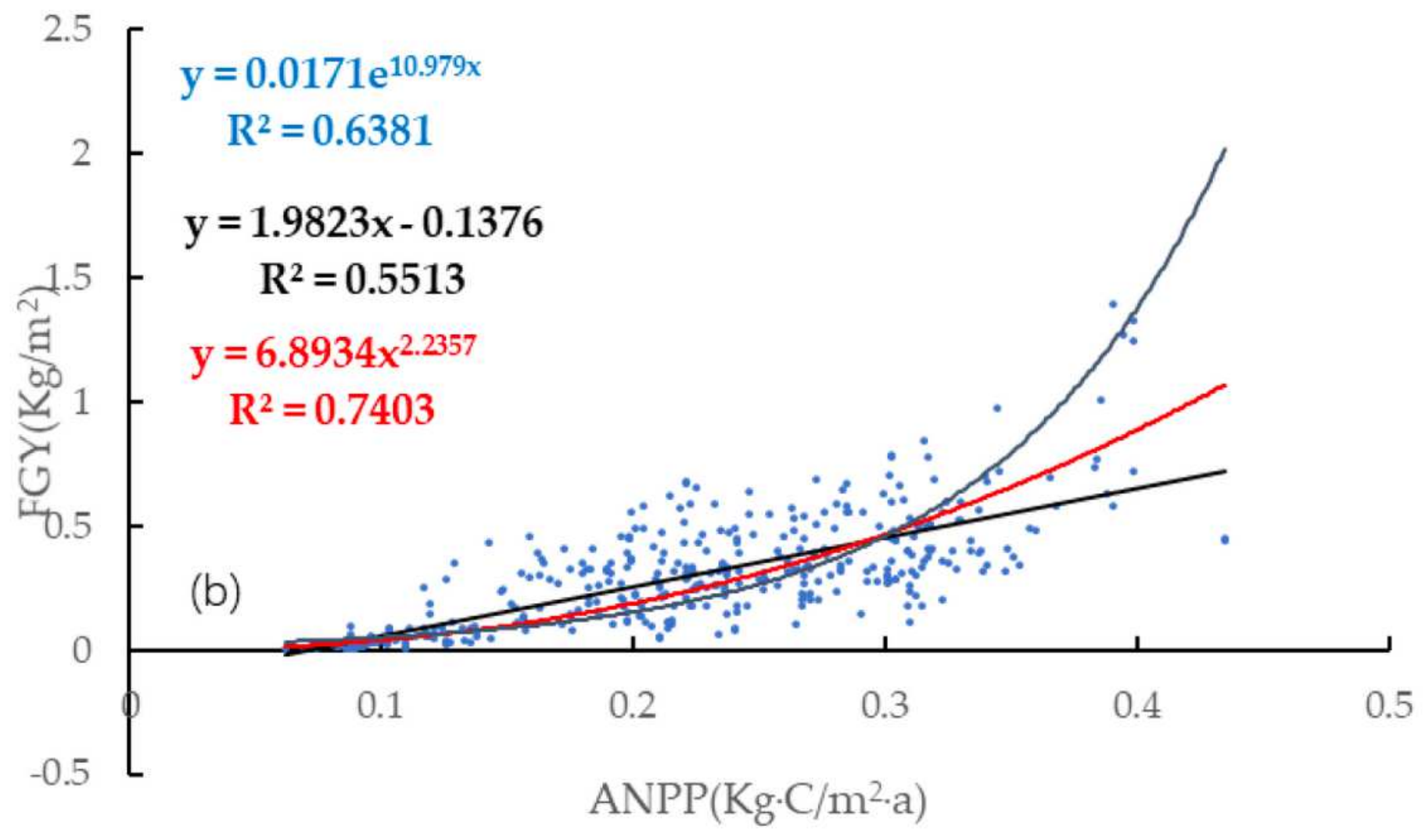

Figure 3

Scatter diagrams constructed using ANPP and FGY. 


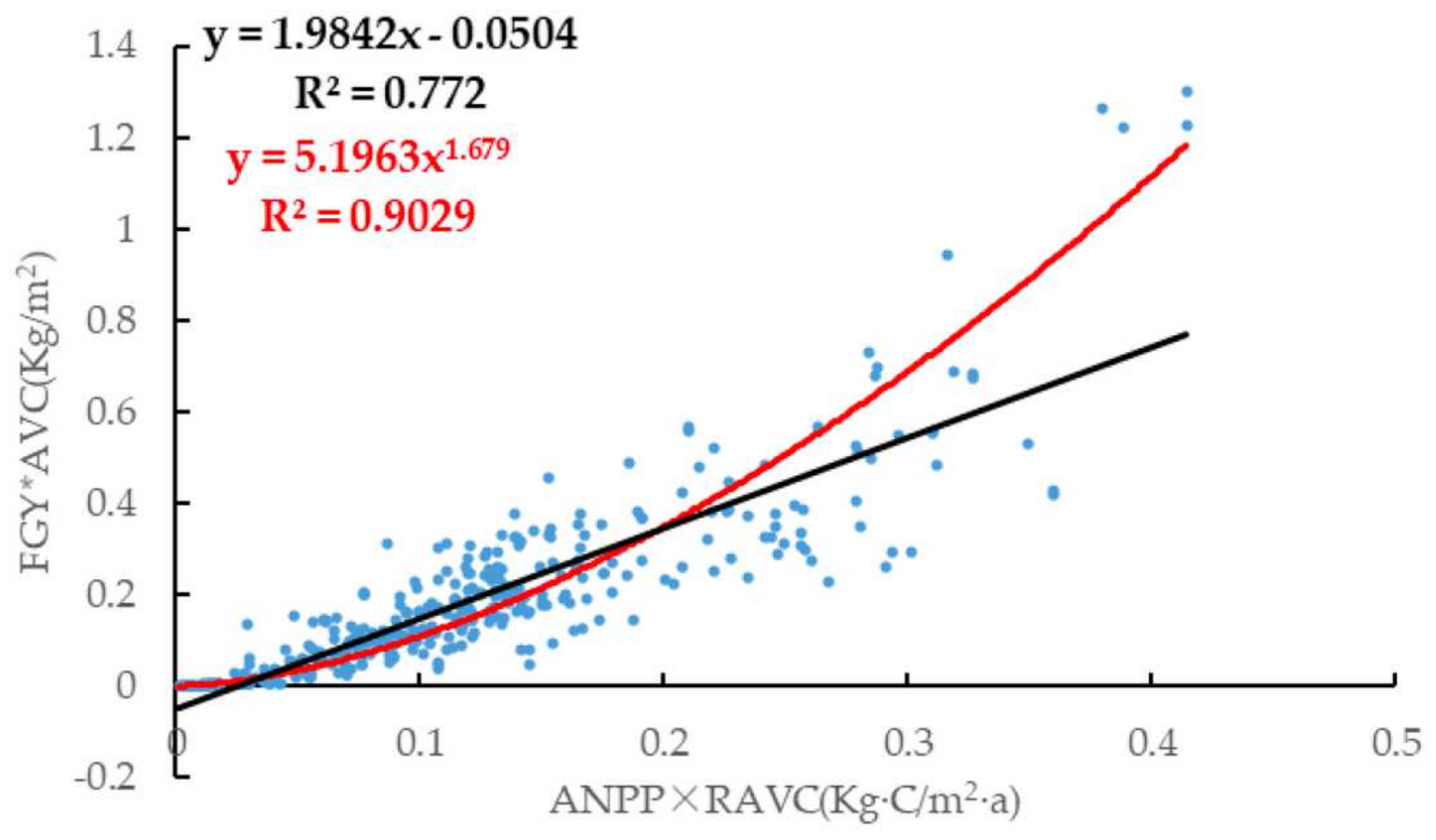

Figure 4

Scatter diagram constructed using AFY $\times$ AVC and ANPP×RAVC. 


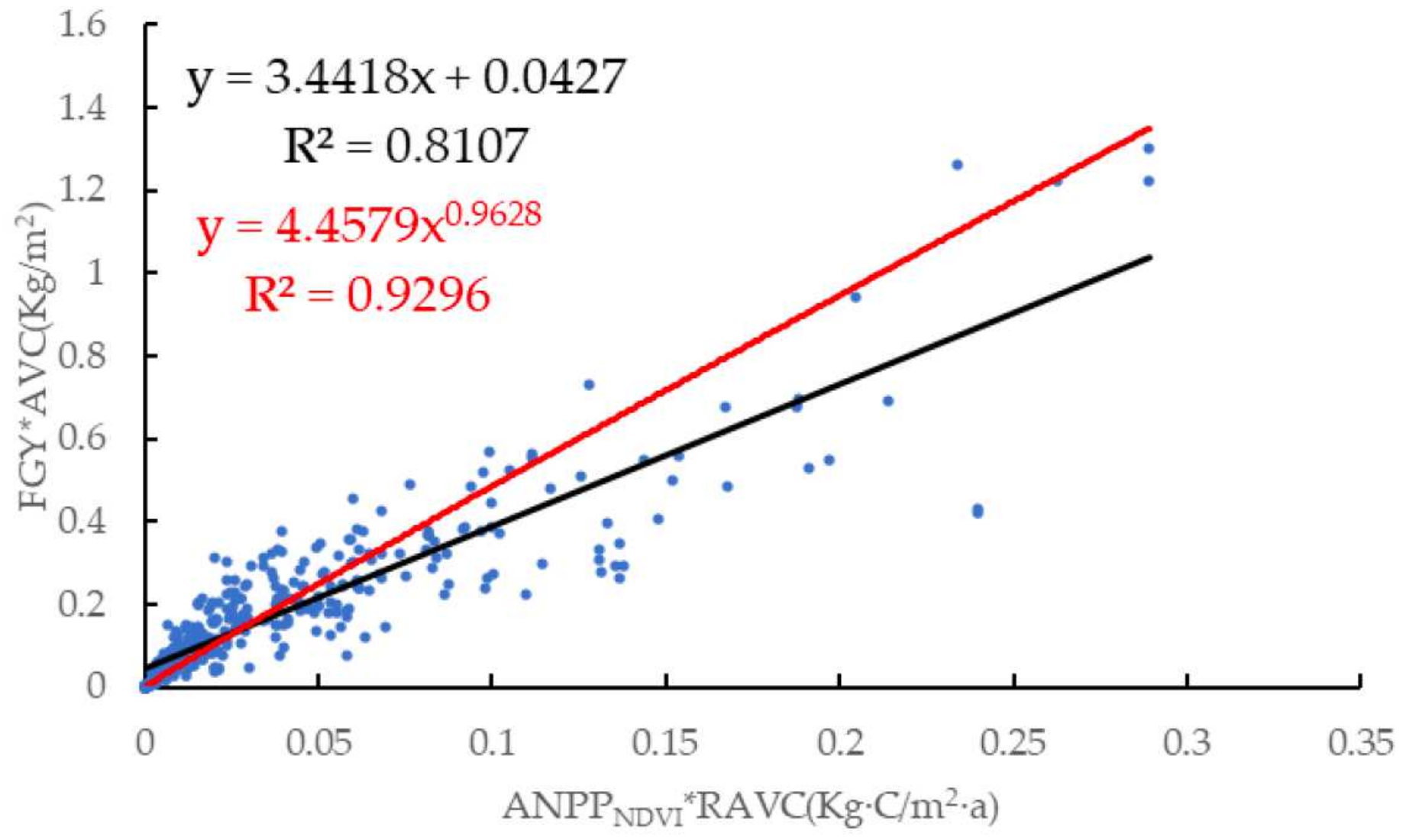

Figure 5

Scatter diagram constructed using AFY $\times A V C$ and ANPPNDVI×RAVC. 


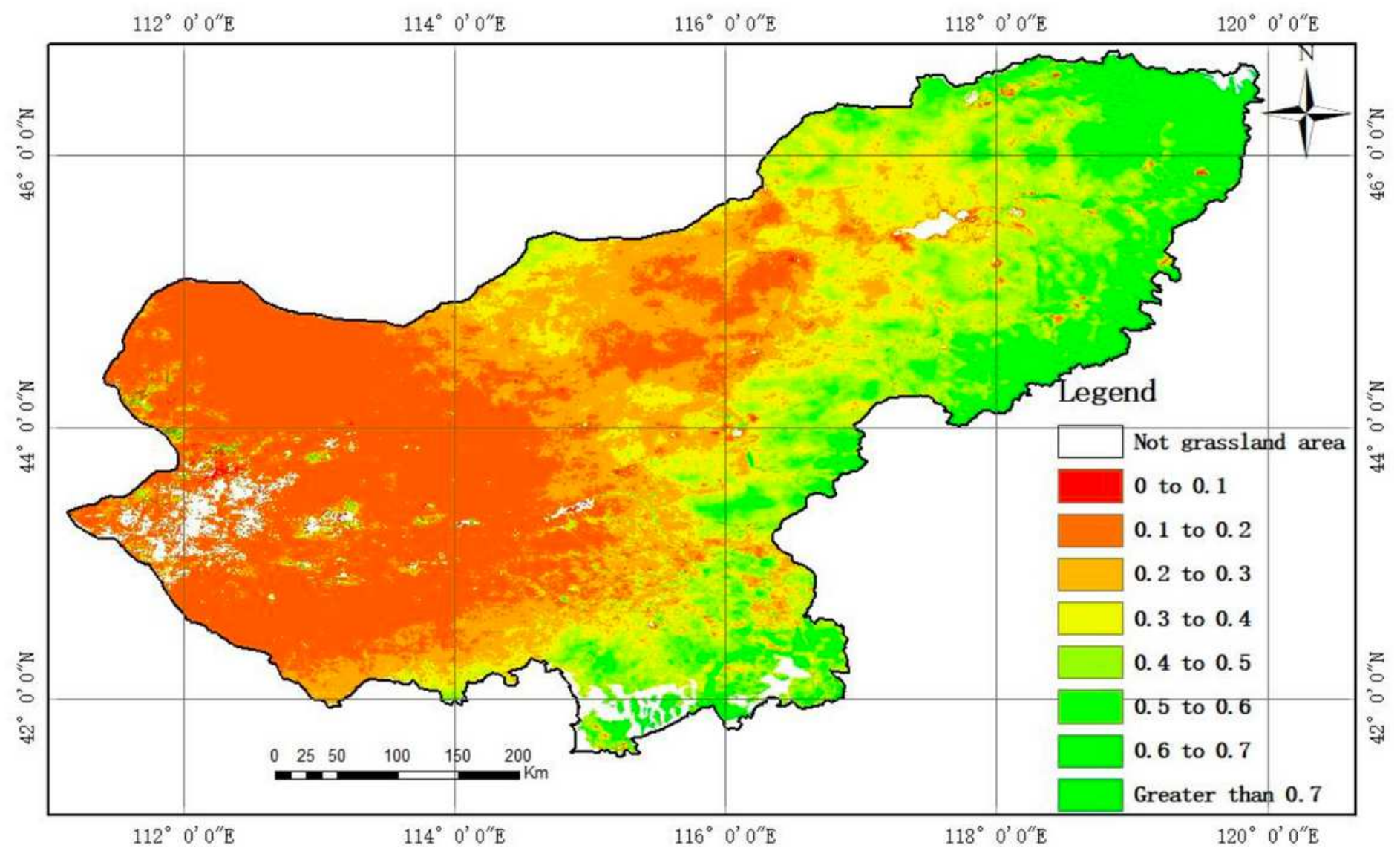

Figure 6

Results estimated by the linear function fitted model. Note: The designations employed and the presentation of the material on this map do not imply the expression of any opinion whatsoever on the part of Research Square concerning the legal status of any country, territory, city or area or of its authorities, or concerning the delimitation of its frontiers or boundaries. This map has been provided by the authors. 


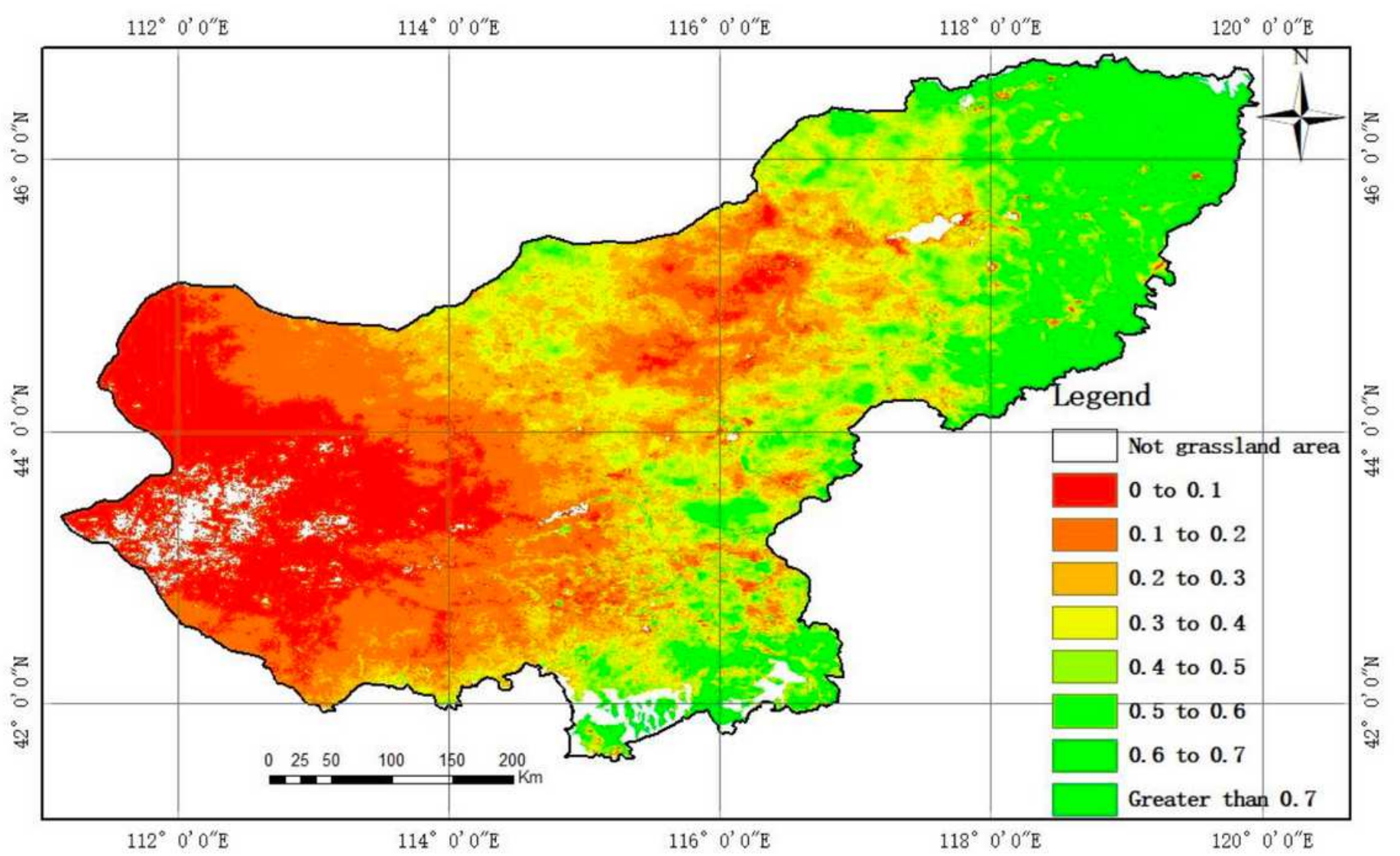

Figure 7

Results estimated by the power function fitted model. Note: The designations employed and the presentation of the material on this map do not imply the expression of any opinion whatsoever on the part of Research Square concerning the legal status of any country, territory, city or area or of its authorities, or concerning the delimitation of its frontiers or boundaries. This map has been provided by the authors. 